\title{
REPENSANDO EL MESTIZAJE
}

\author{
Peter Wade \\ Department of Social Anthropology \\ UNIVERSITY OF MANCHESTER \\ peter.wade@man.ac.uk
}

\begin{abstract}
Resumen
\lfloor A IDEOLOGÍA DEL MESTIZAJE EN AMÉRICA LATINA HA SIDO VISTA CON FRECUENCIA como un proceso que involucra la homogeneización nacional y el ocultamiento de una realidad de exclusión racista detrás de una máscara de inclusión. Se cuestiona esta posición usando el argumento que el mestizaje implica una dimensión permanente de diferenciación nacional y que, mientras que la exclusión es sin duda alguna una realidad, la inclusión es más que una máscara. Usando estudios de caso sobre música popular colombiana, religión popular venezolana y cristianismo popular brasilero se ilustra este argumento, presentando la inclusión como un proceso ligado a relaciones de parentesco e identidades personificadas. En conclusión, se critican las aproximaciones a la hibridez que resaltan su potencial para desestabilizar los esencialismos.
\end{abstract}

Palabras Clave: mestizaje, identidades, nacionalismos, música y culturas populares, reflexividad.

\section{Abstract}

T He ideOlOgY of Mestizaje (MIXTURE) IN LATIN AMERICA HAS FREQUENTLY BEEN seen as involving a process of national homogenization and of hiding a reality of racist exclusion behind a mask of inclusiveness. This view is challenged, with the argument that mestizaje inherently implies a permanent dimension of national differentiation and that, while exclusion is an undoubted reality, inclusion is more than a mask. Case studies drawn from Colombian popular music, Venezuelan popular religion and Brazilian popular Christianity are used to illustrate these arguments and present inclusion as a process linked to embodied identities and kinship relations. In conclusion, a critique is made of approaches to hybridity that highlight its potential for destabilizing essentialisms.

KEY WORDS: mestizaje-miscegenation, identities, nationalisms, popular music and culture, reflexivity.

Revista Colombiana de Antropología

Volumen 39, enero-diciembre 2003, pp. 273-296 
STE ENSAYO* SE PROPONE ENFOCAR UN CONCEPTO CLAVE EN EL MARCO - de las ideas acerca de raza, nación y multiculturalismo en - América latina: el mestizaje. El concepto no es de interés sólo para Latinoamérica, pues en Estados Unidos y Europa cada vez se presta más atención a los procesos y las ideas del mestizaje racial y cultural, aunque en ocasiones bajo otros nombres tales como hibridación, sincretismo, métissage, mélange y creolización, o relacionado con otros conceptos como el de diáspora (Anzal-

* Ponencia para el XIII Congreso de Colombianistas, "Colombia y el Caribe", I2I5 agosto de 2003, Barranquilla, Colombia.

dúa 1987; Bhabha 1994; García Canclini 1995; Gilroy 2000; Hale 1996; Ifekwunigwe 1999; Nelson 1999; Smith I997; Werbner and Modood I997; Young 1995). La multiplicación de los términos referentes al proceso de la mezcla obedece a la percepción de que no hay un solo mestizaje, sino múltiples mestizajes o procesos de mezcla. Sin embargo, en términos de la evaluación a veces se atribuye a estos procesos de mestizaje, hibridación y formación de diáspora algo positivo, porque las mezclas supuestamente rompen con esquemas esencialistas de la identidad y, por tanto, abren la posibilidad de desestabilizar las relaciones jerárquicas del poder que sostienen y dependen de tales esquemas.

Lo que sigue va a ser, en parte, una retrospectiva de mis propios acercamientos al concepto y la realidad del mestizaje en Colombia, y, en parte, una mirada hacia el futuro, explorando nuevas versiones del mestizaje. Concluyo cuestionando a los acercamientos, quizá demasiado optimistas, sobre la hibridación.

\section{INTRODUCCIÓN: EL MESTIZAJE COMO IDEOLOGÍA NACIONALISTA en América latina}

[ L MESTIZAJE HA SIDO VISTO COMO LA BASE PARA LA CONSTRUCCIÓN DE la identidad nacional en muchas naciones de América latina, tanto de parte de las elites nacionales que han asumido la tarea de crear las identidades nacionales, como de los estudiosos que han investigado el proceso histórico de construir la nación. Además, la idea de que "todos somos mestizos" es algo que se escucha y que tiene resonancia en todas las clases sociales de la región. 
En este sentido nacionalista, la ideología del mestizaje se apoya en la idea de que la nación poscolonial se fundamentaba en la mezcla que se dio durante la época colonial entre africanos, indígenas y europeos. La nueva nación independiente llevaría más allá el proceso de mezcla, hacia una nación cada vez más homogénea. Este tipo de ideología ha sido documentada para los casos de Colombia, Ecuador, Brasil, Venezuela y México, entre otros (Graham, I990; Knight, I990; Skidmore, I974; Wade, 1997; Whitten, I98I; Wright, I990; véase también Appelbaum, Macpherson y Rosemblatt, 2003).

La ideología nacionalista del mestizaje tiene amplias variaciones. Por un lado, en algunas naciones o entre diferentes pensadores individuales se adoptó una actitud más positiva hacia el mestizaje. En Brasil y en México posrevolucionario se desarrollaron ideologías bastante positivas de la nación como una entidad mestiza. Se abrazó la identidad de ser mixta como persona y nación, a veces con miras explícitas o tácitas hacia otras naciones -como Estados Unidos- donde la mezcla racial era un tabú y el racismo contra las poblaciones negras e indígenas notorio. Celebrar el mestizaje se convertía en una aseveración de la supuesta democracia racial latinoamericana ${ }^{1}$. En cambio, otras naciones veían el mestizaje como una tacha moral que no podía evitarse pero que podría eliminarse parcialmente por medio de políticas cuasieugenésicas de inmigración ${ }^{2}$.

Paradójicamente, estas dos visiones existían al tiempo dentro de una sola nación. En Brasil, por ejemplo, Gilberto Freyre propulsó la imagen positiva de una nación tropical, basada en la mezcla tri-étnica, mientras al mismo tiempo se fomentaba la inmigración europea y se impedía la inmigración de personas negras. Esta coexistencia de retóricas nacionalistas sobre el valor del mestizaje con prácticas racistas del control de la inmigración no se limitó al caso brasilero ${ }^{3}$.

I. Para una exploración de este proceso de comparación en el caso de Brasil véase Siegel (200I).

2. Sobre el caso de Argentina, véase Helg (I990).

3. Véase Wright (I990) sobre Venezuela.

Dentro de un país puede detectarse que diferentes intelectuales tuvieran actitudes distintas hacia el mestizaje; o, aun, que el mismo intelectual escribiera en tonos contrastantes sobre el mestizaje de acuerdo con su público. Como describí en mi libro Gente negra, nación mestiza, es posible ver un contraste en las actitudes hacia el mestizaje de los intelectuales colombianos 
Luis López de Mesa y Laureano Gómez. Mientras Gómez tenía una visión pesimista del progreso de la nación colombiana, lamentando sus orígenes mestizos y apelando a lo que los colombianos habían heredado del "espíritu español" para guiar la nación, López de Mesa escribía, en su ensayo De cómo se ha formado la nación colombiana -publicado en I934-, que los "obstáculos" que derivaban del mestizaje podían ser superados y que la mezcla no causaba "grave perturbación espiritual” (véase Wade, 1997). Sin embargo, mostraba una cara diferente en un texto destinado a circular entre un comité especial de expertos, en el que habló de "los errores fatales" que representaban algunos tipos de mezcla racial (Wade, 2002).

Otra dimensión de la variación en las ideologías acerca del mestizaje es la importancia diversa que se da a la contribución indígena y a la africana para pensar el imaginario de la nación. En algunos países el mestizaje se ha pensado con referencia más que todo a la mezcla entre blancos e indígenas -por ejemplo, en Perú (De la Cadena, 2000)- mientras en otros el referente básico ha sido la mezcla entre blancos y africanos -por ejemplo, Cuba (Helg, 1995)-. No obstante, es importante entender que, a pesar de estas tendencias, definidas en parte por el peso demográfico de diferentes elementos étnicos en la población total, el mestizaje se imagina siempre como proceso tri-racial. En países donde la presencia demográfica indígena es pequeña -por ejemplo, Colombia donde hoy en día es menos de 2\%; o Brasil, donde actualmente hay unos 250 mil indígenas en una población de unos 165 millones-, los indígenas han sido una presencia central en el pensar la nación. Aun en Puerto Rico, donde la población indígena se eliminó en una época temprana, no son raras las referencias públicas a la cultura indígena taíno, así como a la formación tri-étnica de la nación (Dávila, I997).

Así mismo, en regiones donde la población afro constituía una presencia muy marginal en la nueva nación y hoy en día es casi imperceptible, la imagen de "el negro" desempeñó un rol importante; para las elites nacionalistas en Argentina la imagen de su nación como básicamente no-negra era importante (Savigliano, 1995; Andrews, 1980). Al respecto, es importante recordar el papel que desempeñó la república negra de Haití para las nuevas naciones americanas: para las elites políticas representaba lo que se quería evitar a todo costo. 
En fin, la ideología del mestizaje varía en tanto el énfasis se haga sobre lo indígena o lo afro -sobra decir que lo blanco siempre recibe atención-. Pero el mestizaje latinoamericano no se restringe a la mezcla de dos elementos en el imaginario de la nación; siempre se conjugan las tres imágenes originales.

Con todas sus variaciones, los académicos han visto la ideología del mestizaje como algo exclusivista y fundamentalmente racista. Stutzman lo definió en I98I como "la ideología todo inclusiva de la exclusión”. Es decir, parece ser inclusivo -y las elites nacionalistas la representan como tal-, pero en realidad es exclusiva porque el mestizaje se entiende como un proceso mediante el cual se eliminan paulatinamente las poblaciones negras e indígenas, mientras se blanquea la población nacional (Stutzman, I98I). En su trabajo sobre los indígenas de Nicaragua, Gould refuerza esta visión, describiendo el etnocidio que se llevó a cabo con base en la ideología del mestizaje (Gould, I998).

Más recientemente, otros han observado que el mestizaje en su forma clásica tiene una dimensión de género importante, pues por lo general se trata de un hombre blanco -o más claro- que tiene relaciones sexuales con una mujer más indígena o negra. En la vida real la mezcla implica relaciones de género que muchas veces son relaciones de dominio y poder patriarcal. El hombre tiene la posibilidad de "mezclarse" sin poner en peligro su estatus social ni su vida doméstica; en cambio, la mujer que se "mezcla" en estas relaciones corre el riesgo de verse desprestigiada, de perder su "honor" y de tener el madresolterismo como única opción (Caulfield, 2003; Martinez-Alier, I974; Smith, 1997; Williams, 1996).

Desde este punto de vista, el mestizaje, como ideología nacionalista, generalmente se mira como un proceso más o menos disfrazado de blanqueamiento, tanto en términos físicos como culturales, y de dominio masculino. Este tipo de planteamiento tiene mucha fuerza y mi propósito no es desmentirlo, pero considero que el mestizaje es más complejo, que puede pensarse en múltiples mestizajes y que, para entender por qué la idea del mestizaje y de ser mestizo o producto de un proceso de mezcla tiene tanto arraigo en las poblaciones e imaginarios de las naciones latinoamericanos es necesario ir más allá de la idea del mestizaje como un proceso de exclusión disfrazada. 


\section{Repensando el mestizaje}

\section{Primeros pasos}

L N MI LIBRO GENTE NEGRA, NACIÓN MESTIZA ADOPTÉ ESTA VISIÓN DEL mestizaje como una "ideología todo-inclusiva de la exclusión": el acercamiento de Stutzman que surgió del caso ecuatoriano -y que en muchos sentidos era también el de Whitten- y parecía adecuarse muy bien al caso colombiano (Whitten, I986 [I974]). Aun en ese entonces me pareció que las teorías pos-estructuralistas acerca de la naturaleza relacional de las identidades podrían matizar esta visión; es decir, la idea de que el centro siempre se define en relación con el margen y, por ende, el centro no puede existir sin el margen (Giddens, I987; Hall, I996).

Según este acercamiento, la idea de lo blanco y, con creces, la de la mezcla, depende de la idea de lo negro y lo indígena (Wade, I997). La imagen de la nación necesita la imagen de "los negros" y "los indígenas" -o, dada la dimensión de género que caracteriza el mestizaje, quizás aún más de las negras y las indígenas-. Ahora bien, aun cuando la idea del mestizaje como "ideología todo-inclusiva de la exclusión” reconoce esto en cierta forma, establece una oposición entre la inclusión como mera retórica y la exclusión como la dura realidad detrás de la máscara. Pero a mí me interesaba el rol de los afrocolombianos y los indígenas en constituir la misma idea de la nación, la posibilidad de su existencia. No niego que la ideología del mestizaje incluye elementos importantes de la mera retórica de inclusión, pero creo que va más allá de simple retórica y eso explica algo de su importancia y de su arraigo en las naciones latinoamericanas, en personas de todas las clases sociales.

En esa etapa de mi trabajo no desarrollé estas ideas. En cambio, me centré en la tensión entre lo negro y lo mezclado; en la coexistencia del racismo con la aceptación de la gente negra; y en la coexistencia de la reafirmación de la negritud y la cultura negra con el blanqueamiento. Analicé estas coexistencias, sus tensiones y contradicciones en la nación, la región, la familia y el individuo. En este acercamiento, aunque lo negro y lo mestizo se entretejen, también existen en cierta relación de oposición y no se pone de manifiesto su relación de constitución mutua según la cual cada uno crea las condiciones de posibilidad del otro. 
Desde ese entonces algunas cosas me han llevado a pensar si debería matizarse aún más la idea del mestizaje y sus procesos de inclusión y exclusión. Es importante aclarar que no quiero hacer una apología del mestizaje: me atengo a lo que dije en mi primer libro, que el mestizaje, en su forma nacionalista del blanqueamiento, "lejos de ser indicativo de la ausencia de prejuicio racial, es su principal manifestación en la sociedad de América latina" (Wade, 1997). Sólo pienso que la ideología del mestizaje es compleja y tiene muchos matices. Mis experiencias de investigación en la música colombiana me instaron a pensar más en esos matices.

\section{Investigando la música}

L N I994 EMPRENDÍ UNA INVESTIGACIÓN SOBRE LA HISTORIA SOCIAL DE LA $\sqcup$ música de la región caribeña colombiana en el siglo veinte. Quería explorar cómo esa música pasó de ser una música regional a ser popular en el ámbito nacional y, en cierta medida, llegó a ser la que identifica a Colombia en el ámbito internacional, cómo logró "tropicalizar" a Colombia, cambiando de esa manera la identidad de una nación que antes se jactaba de ser muy europeizada, donde se encontraba la Atenas de Sudamérica, y de tener el corazón de su identidad musical y cultural en la región andina del país.

$\mathrm{Al}$ indagar sobre la música costeña a mediados del siglo veinte me di cuenta de la inmensa producción literaria e intelectual que consideraba la cuestión de la identidad nacional y el lugar de los afrocolombianos -aunque ese término no estaba de moda en esa 4. Para el concepto de la invisibilidad de las poblaciones negras en Colombia y otros países latinoamericanos, véase de Friedemann (I984) y Minority Rights Group (I995). época- y los indígenas en ella (Wade, 2002). Lejos de ser "invisibles", los negros estaban muy presentes en ciertos círculos 4 .

Lo anterior se resaltaba en los escritos sobre la música. Había un énfasis constante sobre los orígenes tri-raciales de la música y la danza, muchas veces dándole un origen racial a elementos muy específicos. En la danza de la cumbia, por ejemplo, es frecuente decir que el hombre es un negro o africano, la mujer indígena y el atuendo europeo; en cuanto a la música, se dice 
que los tambores son el aporte africano, la gaita es indígena $-\mathrm{y}$ según algunos las maracas-, mientras la letra y la armonía son españolas (Wade, 2002; Zapata Olivella, I962). Nótese aquí el hecho de que la mezcla se concibe otra vez como un encuentro sexual de géneros, aunque en este caso -que en términos clásicos es un ejemplo del "zambaje"- el dominante es el africano y no el blanco. Este hecho quizá responda a la predominancia de la población afro sobre la indígena en la región caribeña colombiana, tanto en términos simbólicos como económicos.

Algo fundamental en la ideología del mestizaje se ponía al descubierto: que re-crea las cosas que supuestamente va a eliminar. Lo mestizo no se opone, simplemente, a lo negro y lo indígena -aunque puede haber relaciones de oposición-, sino que las reconstruye activamente. Cada alusión al mestizaje coloca dentro del imaginario los puntos de origen de la mezcla; cada discusión de la cumbia recrea la imagen del encuentro "original" inter-racial. Por ejemplo, las notas de la carátula de un CD de Totó La Momposina sugieren que la música que ella toca tiene sus orígenes en el pasado distante. Las notas describen cómo se han combinado los ritmos africanos y los cuentos románticos españoles, y dice "nuestra música puede describirse como el resultado de un proyecto musical iniciado tal vez hace más de quinientos años" ${ }^{5}$; en otro CD las notas dicen que la cumbia tuvo su origen como "un baile de cortejo cuando hombres negros y mujeres indígenas empezaron a casarse entre sí”. $\mathrm{Al}$ hablar de la música colombiana -y es importante anotar que estas aseveraciones se hacen en el

5. Totó la Momposina, Carmelina (MTM, 7262-008026, 1996).

6. Totó la Momposina y sus Tambores, La candela viva (MTM/Realworld 7260-0080I9, I993); notas originales en inglés. ámbito internacional de la llamada world music- se refiere al mestizaje y al carácter mestizo de la música, pero a la vez se habla de unas poblaciones racializadas y originales.

Ahora, la re-construcción de lo negro y lo indígena no es accidental ni de balde. Es necesaria porque re-establece para las clases dominantes la posibilidad de las distinciones jerárquicas de raza -y, por ende, de clase y de región-, distinciones que amenazan con desparecer si el mestizaje llega a su final ideológico de la homogeneización. Es decir, por un lado las elites pueden aferrarse a la imagen de una nación homogénea -blanqueada-, pero por el otro insisten en la imagen de una nación heterogénea con distinciones de clase, raza y región precisamente porque, como 
elites, requieren y se benefician de las jerarquías establecidas por tales distinciones.

En términos generales, esto sugiere la persistencia de una simbología de orígenes al lado de una del mestizaje: en vez de desaparecerse en una fusión homogénea, perdiendo su identidad, los elementos originales de la mezcla mantienen su presencia en el imaginario del panorama cultural y racial.

Esta manera de pensar el mestizaje parecía armonizarse con la forma en que, durante la investigación sobre música, algunas personas hablaban de sus propias experiencias con la música y la danza en Colombia, como actividades corporales. Parecía haber ideas muy fuertes sobre la música como un tipo de propiedad: estilos de música "pertenecían" a las gentes de ciertas regiones, a pesar de ser la música una producción comercial de circulación nacional y aun internacional: el territorio, la gente y la cultura musical se pensaban como un todo (Wade, 2002). A mi manera de entender, este sentido de propiedad era resultado de la "incorporación" de la música; es decir, la incorporación al hacerla parte del cuerpo por medio de la vida y la actuación. La música se volvió parte de ellos físicamente, tal como la comida que ingirieron -se sabe qué tan fuerte es la identidad regional de la comida en Colombia-, al menos en el imaginario de la gente. Vale la pena contar aquí una anécdota que surgió de la entrevista que se hizo con Antonio María Peñaloza. Él recordaba su llegada a Bogotá en 1940 para tocar en la orquesta de la Emisora Nueva Granada cuando sostuvo una discusión acalorada con el director de la orquesta acerca de la manera correcta de interpretar el bambuco. Según Peñaloza, el director "lo negreó" diciendo, "Oye, negrito, sepa usted que para tocar bambuco hay que comer chunchullo, sobrebarriga y chicha". Se observa el entretejimiento de ideas sobre las capacidades del cuerpo/mente, el origen racial, la región y la comida.

Para la gente el proceso de incorporación abría la posibilidad de apropiarse de nuevos estilos de música y baile al participar físicamente en ellos y hacerlos parte del cuerpo. Al respecto, en las entrevistas era notable cómo la gente del interior del país solía hablar en términos muy físicos y corporales acerca del impacto de la música costeña sobre su región y sus vidas: la manera en que la música les hizo mover la cadera, el calor que producía en ellos y en la misma ciudad donde vivían. Era común que aseveraran que la música costeña -y los mismos costeños- 
habían acalorado, vale decir tropicalizado, la región andina (véase Wade, 2002).

Un ejemplo un poco distinto se encontró en Medellín, donde la música logró despertar algo que ya estaba allí. Un señor antioqueño, un mestizo claro que había sido trompetista en una orquesta, habló de cómo la música costeña siempre lo había atraído porque siempre había tenido un "corazón de negro" (Wade, 2002)7. Además de ser una inversión interesante de la figura estereotipada del "negro con alma blanca", este tro-

7. Entrevista realizada por Manuel po parece indicar una concepción en la Bernardo Rojas.

que pueden tomarse elementos disponibles en el imaginario de los orígenes racializados del panorama música-nación e incorporarlos dentro de cuerpos individuales.

Para que este proceso tenga sentido hay que mirar los planteamientos teóricos sobre el cuerpo, que sostienen que este no es una entidad acabada y completa, sino que es un proyecto sin terminar, en proceso permanente de elaboración o devenir por medio del performance, de la actuación cotidiana; y que el cuerpo no sólo refleja sino que constituye la matriz de relaciones sociales en la cual se encuentra (Butler, I993; Shilling, I993; Wade, 2002). En palabras de Butler, el performance "es una modalidad discursiva por la cual se instalan efectos ontológicos" (citado en Gilroy, 1995). Desde esta óptica puede pensarse en, por lo menos, dos aspectos: I) la realización de elementos latentes que ya están presentes en el cuerpo, pero permanecen quietos, invisibles o desconocidos, como en el caso del hombre con "corazón de negro", que pudo realizar su "corazón” más plenamente cuando la música costeña llegó a Medellín; 2) la adición de elementos nuevos al cuerpo/persona por medio de la incorporación física mediante el vivir y actuar la música y el baile, caso de las personas que hablaban de cómo la música costeña les había suscitado nuevas sensaciones y emociones.

Parece entonces que la "simbología de orígenes" tiene el poder de moldear la formación de la identidad personal-corporal; sus efectos son muy materiales y suelen expresarse mediante ideas acerca del clima, la comida, la música y el baile. Personas que se veían como mestizos, o por lo menos que se reconocían como producto de la mezcla, no necesariamente se veían internamente como un todo homogéneo e indiferenciado. Al contrario, un mestizo o una persona mezclada podía ser como un mosaico de elementos, y a algunos de los elementos se les daba 
una identidad racial derivada de los orígenes tri-raciales de la nación.

\section{María Lionza}

亡 STA VISIÓN DEL MESTIZAJE LA REFUERZA LA TESIS DOCTORAL DE BÁRBARA 4 Plácido sobre las prácticas religiosas que se dan alrededor de la figura de María Lionza en Venezuela (Plácido, I998; véase también Taussig, 1987; Taussig, 1997).

Como se sabe, el culto de María Lionza comprende prácticas y creencias religiosas dirigidas hacia una gama amplia de espíritus y personajes sagrados, entre los cuales se destacan tres figuras centrales, Las Tres Potencias: María Lionza -usualmente una mujer blanca-, El Indio Guaicaipuro -un hombre indígena- y El Negro Felipe.

En primer lugar, se nota que las identidades raciales primordiales que en las narrativas de la nacionalidad dieron origen a la nación siguen siendo símbolos vitales para muchos venezolanos; los elementos originales no se fusionan en un todo nuevo y homogéneo, sino que mantienen su identidad y su poder. Es interesante que el estado ha intentado también apropiarse de algunos aspectos de este complejo religioso: en una escultura grande levantada en Caracas en I952, María Lionza es representada como una mujer indígena montada sobre un tapir. Plácido propone que esta imagen se contrapone a la figura de Simón Bolívar, héroe masculino blanco, dando dos vertientes que representan la nación para los venezolanos. Es de anotar que la versión oficial de María Lionza la convierte en mujer indígena que, yuxtapuesta a Simón Bolívar, mantiene las jerarquías de raza y género que subyacen las ideologías nacionalistas del mestizaje. Sin embargo, Plácido nos muestra la ambivalencia de ambas figuras: "cada espíritu mientras es la representación de un individuo y de una manifestación específica de ese individuo, también contiene y sugiere todas las demás imágenes y posibles manifestaciones" (Plácido, I998). María Lionza parece indígena, pero al cabalgar su tapir evoca a Bolívar montado en su caballo; a la vez sugiere al Negro Felipe al levantar una pelvis humana en sus manos -así aparece en la estatua en Caracas- porque, según los venezolanos con quien hablaba Plácido, la pelvis recordaba los sacrificios 
humanos que supuestamente le hacían sus devotos negros (Plácido, 1998). Mientras tanto, Bolívar, aparentemente el hombre blanco, es objeto desde hace mucho tiempo de rumores sobre su vida, en los que es el hijo ilegítimo de una mujer negra o tiene alguna afinidad con lo negro por haber sido criado por una niñera negra (Plácido, 1998). Entonces, ambas figuras son ambivalentes, con elementos blancos, negros e indígenas dentro de sí.

El trabajo de Plácido nos presenta una perspectiva sobre la identidad nacional venezolana un poco distinta a la imagen del "café con leche", lema que sirve de título al libro de Winthrop Wright sobre la identidad nacional en Venezuela, y que sugiere la fusión irrevocable de elementos que pierden su identidad original en el proceso de síntesis (Wright, 1990). Según Plácido, para los venezolanos que participan en las prácticas de María Lionza "negro, indígena y blanco son partes compuestas de la persona; sin embargo, en el culto de María Lionza estos elementos no deberían fusionarse, sino que las personas deberían mantenerlos separados"; es necesario "contener los diferentes aspectos, pero también mantenerlos separados". Para estos venezolanos, "para ser auténticamente venezolano los seres humanos tienen que ser como Las Tres Potencias, un emblema de la identidad venezolana. Los venezolanos verdaderos no se hacen con la fusión de identidades raciales y étnicas diferentes, no son unidades compuestas de partes, pues las partes no pueden sumarse y no generan unidades" (Plácido, 1998).

Los devotos de María Lionza se distinguen de los "mestizos", aunque se reconocen como personas compuestas de varias partes, como resultado de un proceso de mezcla. Los mestizos son producto de una fusión homogénea, blanqueados, parecidos a Simón Bolívar. Los verdaderos venezolanos son "completos": se parecen a Las Tres Potencias (Plácido, 1998). La presencia dentro de la persona de elementos raciales separados permite la interacción con los espíritus.

En el reino [de María Lionza], las personas, sangres y culturas diferentes pueden encontrarse pero permanecen separadas. El emblema del culto, la imagen de Las Tres Potencias, es una representación clara de cómo las tres razas, de las cuales supuestamente descienden todos los venezolanos, en realidad no se mezclaron para crear un país de mestizos, sino que permanecían como grupos étnicos distintos y separados que componen la nación (Plácido, I998). 
Según los devotos al culto, los mestizos producto de una fusión homogeneizante de los tres orígenes raciales y culturales eran grises, sin color y sin vitalidad y poder. Los auténticos venezolanos, hechos como un mosaico, que tenían adentro las tres potencias -o potencialidades- representadas por los africanos, los europeos y los indígenas, tenían el color, la vivacidad y el poder, y esto se reflejaba en los altares que se construían para venerar a los espíritus, llenos de color y variedad (Plácido, 1998) ${ }^{8}$.

Todo lo anterior nos conduce a una visión del mestizaje un poco diferente de la imagen usual de los procesos nacionalistas de la creación de una identidad homogénea que borra lo negro y lo indígena y termina en un mestizo blanqueado que representa la fusión irrevocable de los orígenes raciales. Nos conduce, en cambio, a una imagen del mestizaje como la construcción de un mosaico.

Es preciso aclarar que no preten-

8. Algo parecido puede verse en otros complejos religiosos como el del Umbanda en Brasil, que, como María Lionza, es una religión de posesión en la cual el devoto es poseído por diferentes espíritus que muchas veces tienen una identidad racial muy clara, como el caso del preto velho (el negro viejo) que puede entrar en el cuerpo de los médiums tanto masculinos como femeninos y tanto negros como blancos (Hale, I997). do plantear esta imagen como una nueva teoría del mestizaje. Se trata, más bien, de un hallazgo etnográfico, de demostrar que para algunas personas, quizá muchas, el mestizaje o el ser mestizo o producto de un proceso de mezcla no encaja bien en la visión del mestizaje como fusión. En cierto sentido, la imagen del mestizaje como mosaico es una visión "desde abajo", o sea un acercamiento al mestizaje desde las clases subordinadas, pero sería un error obligar a este dato etnográfico a caber dentro de un esquema dualista que opone los opresores a los oprimidos. No es tan sencillo, pues el discurso nacionalista dominante reproduce también, muchas veces en una forma tácita e implícita, la versión del mestizaje como mosaico. Plácido, vale la pena anotar, insiste en que el culto de María Lionza, aunque puede tener aspectos de un discurso contra-hegemónico no puede entenderse simple y llanamente como una religión de resistencia al estado, porque el culto es, precisamente, el resultado de un entrecruzamiento de las prácticas y discursos de los devotos, los académicos y el estado; de este modo se ha convertido en un emblema oficial de la nación (Plácido, 1998).

La diferencia entre la concepción de la mezcla vista desde abajo y desde arriba, por decirlo así, no consiste en ver la mezcla como fusión o mosaico, sino en el papel que cumple la jerarquía. Aun 
cuando se piensa en el mestizaje como proceso que conduce a un mosaico, existe la posibilidad de colocar los elementos negros e indígenas en un lugar inferior socialmente, de discriminarlos o volverlos exóticos. Es indispensable tener esto en cuenta, porque si en este acercamiento al mestizaje se plantea que siguen existiendo espacios particulares para lo indígena y lo negro, espacios muchas veces muy personales y corporales, estos espacios siguen estando sujetos a las jerarquías de poder y el valor de las ideologías del blanqueamiento, que favorecen lo blanco y menosprecian lo indígena y lo negro, o que restringen fuertemente el espacio que ocupan, limitando sus derechos.

\section{Mujeres afro-brasileñas y la pastoral negra}

亡 N SU LIBRO SOBRE MUJERES, RAZA Y CRISTIANISMO POPULAR EN BRASIL, $\checkmark$ John Burdick proporciona otros datos sobre el mestizaje (mestiçagem) que ayudan a entender la idea del mosaico y que matizan los procesos de inclusión y exclusión (Burdick, I998).

Burdick describe el impacto de la pastoral negra de la Iglesia católica sobre algunas mujeres afro-brasileñas de las clases populares. Asistiendo a los talleres y clases de la pastoral negra, muchas de estas mujeres se radicalizaron y se concientizaron por medio de sus experiencias de este aspecto institucional del movimiento social negro en Brasil. Muchas empezaron a identificarse abiertamente como "negras" en vez de llamarse "parda" o "prieta." Sin embargo, aun cuando algunas mujeres de ascendencia mezclada a veces se identificaron públicamente como “negras", en contextos más privados valorizaron su ascendencia no-negra, pues esto significaba para ellas nexos muy personales e íntimos con parientes -madres, padres, abuelos, etcétera-. Por ejemplo, una mujer se identificaba como mestiça y explicó este término de la siguiente manera: "Tú sabes, una mezcla. Ni una cosa ni la otra. Mezclado. Mi madre era muy oscura... En realidad, era negra. Y mi padre era más claro. Y hay que ver mis hermanos, son de todos los colores”. Burdick le preguntó por qué no se llamaba negra a sí misma y ella dijo: "Porque no lo soy. Soy una mezcla. Mi madre era negra. Si yo dijera que yo era negra, ¿qué estaría diciendo de mi padre? [Burdick: ¿Es por eso que no te llamas negra?, ¿por tu padre?] Sí, por eso, y porque 
la vida de una negra es muy distinta a lo que ha sido la vida mía” (Burdick, 1998). Para estas mujeres ser mestiza quería decir mantener identificaciones simultáneas, en vez de fusionar todo en una mezcla homogénea en la que los orígenes pierden su sentido.

Lo que quiero destacar de este caso es algo relacionado pero un poco distinto: es importante resaltar que para estas mujeres el mestizaje no era, simplemente, la ideología nacionalista de la elite, sino que se trataba de relaciones personales de familia y parentesco. El mestizaje era una realidad cotidiana para ellas, una realidad de genealogías familiares, de historias personales, de relaciones de amor paternal y filial, de relaciones sexuales. El mestizaje no es, simplemente, una "ideología todo-inclusiva de la exclusión”, ni los discursos nacionalistas de la elite y las políticas de inmigración y de discriminación racial, es también una práctica cotidiana, en la que la "inclusión" no es mera retórica sino un aspecto de la realidad vivida y sentida.

Repito que esto no se convierte en una apología del mestizaje. No estoy planteando que el mestizaje "en realidad" es un proceso necesariamente benévolo porque tiene aspectos de inclusión que van más allá de la mera retórica. Sólo quiero decir que es más complejo de lo que a veces se dice, que hay diferentes procesos e ideas de lo que es la mezcla, que hay diferentes mestizajes; y que existen procesos de inclusión que son reales y que tienen un significado vivido para la gente. Con esto no niego, de ninguna manera, que también existen fuertes procesos de exclusión.

\section{El entretejimiento de la inclusión y la exclusión}

ODEMOS VER unos EJEMPLOS BREVES DE CÓMO LOS DOS PROCESOS
de inclusión y exclusión se entrelazan. El primer caso viene de mi trabajo de campo en Medellín y es el de una madre negra, oriunda del departamento de Chocó, que tuvo cuatro hijas con su marido negro chocoano antes de que este muriera en un accidente de tránsito. Sus hijas todas se casaron o tuvieron hijos con hombres antioqueños blancos/mestizos.

Para la madre y sus hijas el mestizaje era una realidad vivida que surgió del contexto urbano en que se encontraban: los hombres jóvenes que había a su alrededor eran antioqueños blancos 
y mestizos. Las relaciones que se establecían con ellos podían ser permanentes o pasajeras, buenas y malas, pero crearon procesos de inclusión, sobre todo para los hijos de esas uniones. La realidad cotidiana del mestizaje la constituían las relaciones de parentesco que surgieron de las nuevas familias. Pero la madre se quejaba de que otras familias chocoanas de la vecindad la tildaban a ella y a sus hijas de racistas, porque según esas otras familias las hijas estaban rechazando a los negros como parejas y, por tanto, también a su propia condición de ser negras.

Así, el proceso del mestizaje estaba sujeto a unas evaluaciones morales que tienen sus raíces en las jerarquías raciales que corresponden al dominio de lo blanco y, en este caso, a la resistencia que establecía la gente negra contra ese dominio, que es un dominio vivido y sentido también por parte de los chocoanos en Medellín por medio del racismo que experimentan a veces. Casarse o tener hijos con un blanco era visto, por algunas familias negras, como una traición a la comunidad negra, un acto de mestizaje que no era sino un desdoblamiento a las ideologías del blanqueamiento. Al tildar a esta familia de racista -es decir, racista contra los mismos negros- se impuso un proceso de exclusión que difería de la definición inclusiva del mestizaje a la que adherían la madre y sus hijas, sin que ellas ignoraran la fuerza de aquel calificativo.

Vale la pena pensar, otra vez, en la dimensión del género en este caso. La crítica, ¿habría sido tan

9. Para una discusión del significado de las uniones mixtas véase Wade (I997). fuerte si se tratara de cuatro hijos que habían entablado relaciones con mujeres blancas y mestizas? ${ }^{9}$.

Carol Smith nos da otro ejemplo en su artículo "The symbolics of blood: mestizaje in the Americas" (Smith, 1997), en el que describe el mestizaje en la zona cafetera de Colombia durante la segunda mitad del siglo diecinueve. Debido al auge cafetero, las familias campesinas mestizas de la zona entraron en contacto más intenso con hombres más blancos y económicamente más poderosos, quienes utilizaron, a veces, su posición dominante para entablar relaciones sexuales con las mujeres mestizas, a veces en una forma depredadora.

En algunas ocasiones las mujeres mestizas pudieron aprovecharse de la situación, ganando cierto grado de independencia económica y doméstica por medio de sus relaciones con estos 
hombres. La frecuencia del madresolterismo y hogares con jefe femenino aumentó. La reacción de los hombres mestizos era, por un lado, de utilizar las mismas formas de depredación sexual contra las mismas mujeres mestizas y, por el otro, tratar de proteger a "sus" mujeres dentro del hogar familiar y restringir la posibilidad de que ellas establecieran relaciones con los hombres ricos. En ambos casos los hombres mestizos estaban intentando mantener su condición de hombre dominante sobre la mujer, o bien por el asedio sexual o bien por la protección doméstica.

En este caso, entonces, la realidad del mestizaje fue múltiple: había el mestizaje de los campesinos antes del auge cafetero -del cual no habla mucho Smith-; siguió el impacto de un mestizaje más rapaz en términos de raza y género. Había la posibilidad de mayor inclusión económica para algunas mujeres, pero también la sensación de parte de los hombres mestizos de verse amenazados por la exclusión de su condición de "hombre".

\section{Conclusión}

STOY ABOGANDO POR UNA VISIÓN EN LA QUE EL MESTIZAJE ES MÚLTI- ple y tiene muchos significados, entre ellos la imagen de un L mosaico, hecho de diferentes elementos y procesos, que pueden manifestarse dentro del cuerpo, dentro del ámbito familiar, así como dentro de la nación. Visto así, el mestizaje deja espacios posibles a muchos elementos, inclusive a elementos de identidades negras e indígenas, e implica procesos de inclusión que van más allá de simples retóricas discursivas y máscaras superficiales. De allí quiero sacar tres conclusiones generales.

Primera. Para mí, el mestizaje visto de esta manera es lo que marca la situación latinoamericana como sui generis y distinta a la de Estados Unidos. En las discusiones sobre la comparación entre Estados Unidos y Brasil, en términos raciales, algunos han sostenido que los dos países son opuestos (Harris, I974), otros que ya se van acercando (Skidmore, I993) y otros más que sigue habiendo una diferencia importante (Ferreira da Silva, 1998; Fry, 2000; véase también Hanchard, 1999). Estoy de acuerdo con los últimos y considero que el juego ambivalente y ambiguo entre la inclusión y la exclusión, y la realidad vivida de la inclusión es lo que marca la diferencia. 
Segunda. Es fundamental entender que el mestizaje y sus componentes siempre están sujetos a las jerarquías del poder político y económico, y a las jerarquías del racismo. No pueden escapar de ellas. Reconocer esto nos da una visión crítica de los teóricos que plantean que el hibridismo y las relaciones de la diáspora rompen necesariamente con las identidades esencialistas y, de esa manera, pueden retar a las relaciones de poder dominantes. Papastergiadis (1997) observa que Stuart Hall, Homi Bhabha y Gayatri Spivak se citan frecuentemente al respecto y que "en el ámbito más general del debate conceptual parece haber un consenso en cuanto a la utilidad del hibridismo como antídoto contra la subjetividad esencialista”. Hale (I996) anota también una tendencia reciente entre algunos latinoamericanistas a vincular "identidades híbridas en América latina a nuevas formas prometedoras de la oposición política”. Varias personas han criticado el empleo de metáforas del mestizaje y el hibridismo para describir la realidad latinoamericana. Cornejo-Polar, por ejemplo, afirma que estas metáforas no hacen sino "ofrecer imágenes armónicas de lo que obviamente es desgajado y beligerante, proponiendo figuraciones que en el fondo sólo son pertinentes a quienes conviene imaginar nuestras sociedades como tersos y nada conflictivos espacios de convivencia” (Cornejo-Polar, 1997). Kokotovic también discrepa del concepto de hibridismo cultural, como lo emplea García Canclini (I990), pues “oculta más que revela de la concentración de poder y la centralización de la cultura" (Kokotovic, 2000).

Sin embargo, los teóricos del hibridismo siguen atribuyendo una fuerza positiva a los procesos de la mezcla y no ignoran sus posibles aspectos negativos (García Canclini, I999). En los escritos de Stuart Hall, por ejemplo, pueden detectarse dos modelos de hibridismo (Young, 1995). Para él, y creo que para Gilroy (2000) también, la mezcla no es necesariamente positiva, pues depende de la modalidad. La primera modalidad es la mezcla que siempre retorna a los orígenes, que depende de cálculos genealógicos de la identidad, que evoca metáforas biológicas, hasta eugenésicas, y que reitera ideas fáciles de un sincretismo en que dos identidades puras se mezclan para producir un hijo mixto. En esta modalidad de la mezcla se reproducen los esencialismos y no se desestabilizan las relaciones del poder dominante.

El segundo modelo de la mezcla es de un proceso impredecible, movedizo, algo que tiene poco que ver con los simples cálculos 
genealógicos y que es más al estilo de las mezclas musicales y textuales que hoy en día la tecnología digital ha hecho posible y que crean redes de relaciones rizomatosas que se extienden en todas direcciones sin estructura fija y sin rumbo predecible.

De acuerdo con Young (1995) la hibridación como creolización se basa en la fusión, en la creación de formas nuevas que después se contraponen a las formas viejas, de las cuales en parte se componen. La hibridación como el caos no-racial, en cambio, no produce ninguna forma estable sino algo más cercano a lo que describe Bhabha como el hibridismo inquieto, intranquilo, intersticial: una heterogeneidad radical, la discontinuidad, la transformación permanente de las formas.

Esta dualidad del hibridismo se nota también cuando Gilroy habla de los escritos de dos esclavos del siglo dieciocho, llamados Equiano y Wheatley. Gilroy (2000) comenta que sus trabajos como "formaciones complejas y compuestas" dejan una herencia que es "una mezcla, un híbrido". Sigue: "Su forma recombinante les debe mucho a sus culturas 'paternas' pero sigue siendo un bastardo convencido y insubordinado. De ninguna manera reproduce en forma no-modificada a ninguna de las dos supuestas purezas anteriores que le dieron origen”. En cambio, las identidades híbridas de la diáspora, son entidades que "se reprocesan sin fin". La diáspora es "siempre promiscua" y nos reta a "comprender las formas mutables que pueden redefinir la idea de la cultura mediante una reconciliación con el movimiento y la variación compleja y dinámica” (Gilroy, 2000).

Hall y Gilroy reconocen dos formas de mezclar pero ven en la segunda un antídoto a la primera. Me parece que el material latinoamericano indica que estos dos modelos de la mezcla son los lados opuestos de una misma moneda: el uno nunca puede deshacerse del otro; y el segundo no puede suprimir el primero. Toda mezcla híbrida, de la diáspora, rizomatosa, que parece desechar los orígenes, deshacer los esencialismos y retar a las jerarquías tiene como doble la forma de mezcla que reitera y recrea los orígenes y que juega con elementos primordiales relativamente fijos. Ahora, reiterar los orígenes no es algo que conduce, necesariamente, a los esencialismos ni a las jerarquías. La mezcla como mosaico también puede deshacer las identidades esenciales: si la persona se concibe como un mosaico de elementos de alguna manera se aleja de una definición esencial de sí misma. Pero, como hemos visto, primero, los elementos del mosaico 
se prestan fácilmente a la esencialización: al hablar de tener un "corazón de negro" se evoca una imagen del "negro" bastante estereotipada y esencialista. Y, segundo, como he tratado de demostrar, es muy difícil que la mezcla evite la jerarquización de los elementos.

En este sentido -tercera y última conclusión- el mestizaje es un espacio de lucha. No es una razón para ser automáticamente optimista, porque implica desestabilización y movimiento de diáspora; ni es una razón para que los latinoamericanos se duerman en los laureles porque el mestizaje puede tener efectos de inclusión. Es una lucha para ver qué va a ser incluido y excluido, y para ver hasta dónde pueden retarse las jerarquías de poder.

Esta lucha sigue en Colombia. Es indudable que el panorama pluriétnico y multicultural establecido por la constitución de I99I abre nuevos espacios, pero yo los entiendo como versiones nuevas de una realidad pre-existente, en vez de ser una ruptura total con el pasado. Si en la ideología del mestizaje siempre existía un espacio, aunque restringido, para lo negro y lo indígena, la nueva constitución no introduce algo inaudito y radicalmente nuevo, sino que adapta y transforma formas ya conocidas. Las mismas luchas siguen vigentes y es evidente que, a pesar de los derechos importantes para las comunidades afrocolombianas e indígenas que introdujeron la constitución y la legislación posterior, el control político y económico dominante sigue restringiendo fuertemente los derechos de estas comunidades. Por eso sigue la lucha para definir para lo afrocolombiano y lo indígena espacios dignos de una sociedad democrática.

\section{BibliografíA}

Andrews, George Reid. 1980. The Afro-Argentines of Buenos Aires, I800-1900. Madison. University of Wisconsin Press.

AnZaldúa, GloRia. 1987. Borderlands/la frontera: the new mestiza. San Francisco. Aunt Lute Books.

Appelbaum, Nancy P., Anne S. Macpherson y Karin A. Rosemblatt (eds). 2003. Race and nation in modern Latin America. University of North Carolina Press. Chapel Hill.

Внавна, Hомi. 1994. The location of culture. Routledge. Londres. 
Burdick, John. 1998. Blessed Anastácia: women, race, and popular Christianity in Brazil. Routledge. Londres.

Butler, Judith P. I993. Bodies that matter: on the discursive limits of 'sex'. Routledge. Londres.

Caulfield, Sueann. 2003. "Interracial courtship in the Rio de Janeiro courts, I9I8-I940". En Race and nation in modern Latin America. N. P. Appelbaum, A. S. Macpherson y K. A. Rosemblatt (eds). University of North Carolina Press. Chapel Hill.

Cornejo-Polar, Antonio. i997. "Mestizaje e hibridez: los riesgos de las metáforas: apuntes”. Revista Iberoaméricano LXIII (I80).

DÁvila, Arlene. I997. Sponsored identities: cultural politics in Puerto Rico. Temple University Press. Philadelphia.

De Friedemann, NinA. I984. "Estudios de negros en la antropología colombiana”. En Un siglo de investigación social: antropología en Colombia. J. Arocha y N. de Friedemann. Etno. Bogotá.

De la Cadena, Marisol. 200o. Indigenous mestizos: the politics of race and culture in Cuzco, I9IO-I99I. Duke University Press. Durham.

Ferreira da Silva, Denise. I998. "Facts of blackness: Brazil is not (quite) the United States ... and racial politics in Brazil?” Social Identities. 4 (2).

Fry, PETER. 2000. "Politics, nationality, and the meanings of 'race' in Brazil”. Daedalus. I29 (2).

García Canclini, Néstor. I990. Culturas híbridas: estrategias para entrar y salir de la modernidad. Grijalbo. México.

- I995. Hybrid cultures: strategies for entering and leaving modernity. Traducción de C. L. Chippari y S. L. López. Minneapolis. University of Minnesota Press.

—. I999. "Entrar y salir de la hibridación”. Revista de Crítica Literaria Latinoamericano. XXV (50).

Giddens, Anthony. 1987. Social theory and modern society. Cambridge. Polity Press.

Gilroy, PAul. I995. “... to be real': the dissident forms of black expressive culture”. En Let's get it on: the politics of black performance. C. Ugwu. Institute of Contemporary Arts and Bay Press. Londres y Seattle.

of race. Penguin Books. Londres.

Gould, JEFFrey L. I998. To die in this way: Nicaraguan Indians and the myth of the mestizaje, I880-1960. Duke University Press. Durham. 
Graham, Richard (ed.). I990. The idea of race in Latin America, I870-I940. Austin. Texas.

Hale, Charles R. I996. "Mestizaje, hybridity and the cultural politics of difference in post-revolutionary Central America”. Journal of Latin American Anthropology. 2 (I).

Hale, Lindsay L. I997. "Preto velho: resistance, redemption, and engendered representations of slavery in a Brazilian possessiontrance religion”. American Ethnologist. 24 (2).

Hall, Stuart. I996. "Introduction: who needs identity?”. En Questions of cultural identity. S. Hall y P. d. Gay(eds.). Sage. Londres.

Hanchard, Michael, ed. I999. Racial politics in contemporary Brazil. Duke University Press. Durham.

Harris, Marvin. I974. Patterns of race in the Americas. 2nd ed. Norton Library. Nueva York.

Helg, Aline. I990. "Race in Argentina and Cuba, I880-I930". En The idea of race in Latin America, I870-1940. R. Graham (ed.). University of Texas Press. Austin.

. I995. Our rightful share: the Afro-Cuban struggle for equality, I886-I9I2. University of North Carolina Press. Chapel Hill.

IfEKWunigwe, Jayne O. I999. Scattered belongings: cultural paradoxes of "race," nation and gender. Routledge. Londres.

Knight, Alan. I990. "Racism, revolution and indigenismo Mexico, I9IO-I940". En The idea of race in Latin America. R. Graham (ed.). University of Texas Press. Austin.

Kокотоvic, Misha. 2000. "Hibridez y desigualdad: García Canclini ante el neoliberalismo”. Revista de Crítica Literaria Latinoamericano. XXVI (52).

Martinez-Alier, VerenA. I974. Marriage, colour and class in nineteenthcentury Cuba. Cambridge University Press. Cambridge.

Minority Rights Group (ed.). I995. No Longer Invisible: Afro-Latin Americans Today. Minority Rights Group. Londres.

Nelson, Diane M. 1999. "Perpetual creation and decomposition: bodies, gender, and desire in the assumptions of a Guatemalan discourse of mestizaje". Journal of Latin American Anthropology. 4 (I).

PAPAstergiadis, Nikos. I997. "Tracing hybridity in theory”. En Debating cultural hybridity: multi-cultural identities and the politics of anti-racism. P. Werbner y T. Modood (eds.). Zed . Books. Londres.

PlÁCIDO, BARBARA. I998. "Spirits of the nation: identity and legitimacy 
in the cults of María Lionza and Simón Bolívar”. PhD. University of Cambridge. Cambridge.

Savigliano, Marta E. I995. Tango and the political economy of passion. Westview Press. Boulder.

Shilling, Chris. I993. The body and social theory. Sage. Londres.

SiEgEL, Micol. 200I. "The point of comparison: transnational racial construction, Brazil and the United States, I9I8-I933”. PhD, New York University. Nueva York.

Skidmore, Thomas. 1974. Black into white: race and nationality in Brazilian thought. Oxford University Press. Nueva York. . I993. "Bi-racial USA vs. multi-racial Brazil: is the contrast still valid?”. Journal of Latin American Studies. 25.

Smith, Carol A. I997. "The symbolics of blood: mestizaje in the Americas”. Identities. 3 (4).

Stutzman, Ronald. I98I. "El mestizaje: an all-inclusive ideology of exclusion”. En Cultural transformations and ethnicity in modern Ecuador. N. E. Whitten (ed.). University of Illinois Press. Urbana.

TAussig, Michael. I987. Shamanism, colonialism and the wild man: a study in terror and healing. Chicago University Press. Chicago.

WADE, PETER. I997. Gente negra, nación mestiza: las dinámicas de las identidades raciales en Colombia. Traducción de Ana Cristina Mejía. Ediciones Uniandes-Ediciones de la Universidad de Antioquia-Siglo del Hombre Editores-Instituto Colombiano de Antropología. Bogota.

2002. Música, raza y nación: la música tropical en Departamento Nacional de Planeación. Bogota.

- 2002. Race, nature and culture: an anthropological perspective. Pluto Press. Londres.

Werbner, Pnina y Tariq Modood (eds.). I997. Debating cultural hybridity: multi-cultural identities and the politics of anti-racism. Zed Books. Londres.

Whitten, Norman. I986 [1974]. Black Frontiersmen: A South American Case. 2nd ed. Waveland Press. Prospect Heights, Illinois.

-. (ed.). I98I. Cultural transformations and ethnicity in modern Ecuador. University of Illinois Press. Urbana.

Williams, BRACKETte (ed.). I996. Women out of place: the gender of agency and the race of nationality. Routledge. Nueva York. 
Wright, Winthrop. ig9o. Café con leche: race, class and national image in Venezuela. University of Texas Press. Austin.

Young, Robert. I995. Colonial desire: hybridity in theory, culture and race. Routledge. Londres.

Zapata Olivella, Delia. I962. "La cumbia: síntesis musical de la nación colombiana; reseña histórica y coreográfica". Revista Colombiana de Folclor. 3 (7). 